\title{
Erratum to: Prevalence and characteristics of hepatitis B and C virus infections in treatment-naïve $\mathrm{HIV}$-infected patients
}

\author{
Stefan Reuter $\cdot$ Mark Oette $\cdot$ Frank Clemens Wilhelm $\cdot$ Bastian Beggel $\cdot$ Rolf Kaiser • \\ Melanie Balduin · Finja Schweitzer · Jens Verheyen · Ortwin Adams · Thomas Lengauer • \\ Gerd Fätkenheuer · Herbert Pfister · Dieter Häussinger
}

Published online: 30 October 2010

(C) Springer-Verlag 2010

\section{Erratum to: Med Microbiol Immunol}

DOI 10.1007/s00430-010-0172-z

Authors regret that an error was found in Table 1 last line which was already published in online first.

Table 1 last line, first row, should be named "HBsAg neg. (n)" instead of "HBsAg pos. (n)".

The online version of the original article can be found under doi:10.1007/s00430-010-0172-z.

S. Reuter $(\bowtie) \cdot$ D. Häussinger

Clinic of Gastroenterology, Hepatology and Infectious Diseases, University Hospital, Moorenstr. 5, 40225 Duesseldorf, Germany

e-mail: Stefan.reuter@med.uni-duesseldorf.de

\section{Oette}

Clinic of General Medicine, Gastroenterology and Infectious

Diseases, Augustinerinnen Hospital, Cologne, Germany

F. C. Wilhelm - R. Kaiser - M. Balduin · F. Schweitzer

J. Verheyen $\cdot$ H. Pfister

Institute of Virology, University of Cologne, Cologne, Germany

B. Beggel · T. Lengauer

Max Planck Institute for Informatics, Computational Biology

and Applied Algorithmics, Saarbruecken, Germany

O. Adams

Institute of Virology, University Hospital of Düsseldorf,

Düsseldorf, Germany

G. Fätkenheuer

Department of Internal Medicine I, University Hospital

of Cologne, Cologne, Germany 